\title{
Fear of the Unseen
}

\author{
Brandon Sprung $^{1} \cdot$ Christine Granato $^{1} \cdot$ Danielle Marino $^{1}$
}

Published online: 20 January 2016

(c) Springer Science+Business Media New York 2016

\section{Why Should I Worry About Missing Colon Polyps or Cancer?}

As a young gastroenterologist, you may be faced with interval colon cancers or missed polyps at some point in your career. Due to variable lesion growth rates, there is inevitably an inherent miss rate of colonoscopy even if you use optimal examination techniques. The thought of missed polyps or cancers can be anxiety-provoking for young endoscopists, bringing with it the potential for significant medical and legal ramifications. In fact, colonoscopy represents the highest frequency of closed claims and indemnities among all endoscopic procedures [1]. Unfortunately, fear of litigation surrounding the development of interval colon cancers leads to overuse of colonoscopy for surveillance and inappropriate application of colorectal cancer surveillance guidelines, both of which are now tracked as part of your physician performance measures. In legal cases of missed or interval cancers, focus lies on determining whether the "standard of care" was met for the procedure in order to determine whether negligence occurred; if you practice within established standards of care, you will be a more difficult target for litigation.

As trainees, we take comfort in knowing that the watchful eyes of our attending are there to see what we may not, at times even repeating the examination themselves. As training transitions into independent practice, those watchful eyes slowly fade, leaving us without this security. Fortunately, several established steps can be taken

Brandon Sprung

brandon.sprung@gmail.com

1 Division of Gastroenterology and Hepatology, University of Rochester Medical Center, Rochester, NY, USA to ensure standards of care are met and thus protect your patients from the tragedy and you from the medicolegal ramifications of a missed polyp or cancer.

\section{How Important Is Informed Consent?}

One of the most important steps that need to be taken to protect yourself and your patient is to obtain appropriate preprocedural informed consent. Properly obtained informed consent allows a competent individual to legally and ethically exercise their right to the autonomy of medical decision making by providing disclosure of risks, benefits, and alternatives. In malpractice cases involving deficits of informed consent, both failure of the provider to disclose reasonable complications of the procedure and failure to obtain proper informed consent are generally relied upon for litigants. The first aspect of informed consent to colonoscopy should involve your documentation of your discussion of the proper indications for, the benefits of, and the alternatives to the planned procedure. Procedures which are not appropriately indicated have been targeted in up to $4 \%$ of medicolegal endoscopy claims against gastroenterologists [1]. For colorectal cancer screening, you should discuss that colonoscopy is the accepted "gold standard" for detecting and preventing colon cancer, and you should also review alternatives such as fecal occult blood testing in order to provide the patient with knowledge of alternative screening options. Furthermore, you should discuss potential risks with your patient, using details sufficient to satisfy what a reasonable person would want to know and what a reasonable physician would choose to disclose [2]. There are a plethora of possible complications of colonoscopy which are generally too numerous to detail within the time constraints of clinical practice. It is, however, important to touch on a few more common risks, specifically 
bleeding, perforation, sedation side effects, and having to return sooner than expected due to a poor bowel preparation or a technically challenging examination. You should also discuss the possibility of a missed polyp or cancer, as even the most thorough examination has an inherent miss rate. Studies on tandem colonoscopy for adenoma detection have reported an overall miss rate of up to $22 \%$, even higher for diminutive polyps [3]. While most of these polyps will not ultimately become cancer, it is important to set appropriate expectations with your patients by explaining that colonoscopy is an imperfect test.

\section{What Should I Document During Colonoscopy to Protect Myself and My Patient?}

Photographic documentation of cecal intubation, the standard of medical care in the USA, should be obtained in $>95 \%$ of screening colonoscopies in order to confirm examination completion [4]. A verbal description of cecal intubation, including cecal landmarks (ileocecal valve, appendiceal orifice, cecal strap, and ileal intubation if performed), should also be included in the procedure report [4].

The diagnostic accuracy of colonoscopy requires adequate visualization of the colonic mucosa, emphasizing the importance of excellent bowel preparation. The American Society for Gastrointestinal Endoscopy (ASGE) and American College of Gastroenterology (ACG) joint task force recommend that the examination is adequate if it allows detection of polyps $>5 \mathrm{~mm}$ in diameter [5]. Poor bowel preparation can prolong cecal intubation and withdrawal times while reducing the detection of polyps [6]. You should consider using one of several scoring systems available to provide an objective assessment of bowel preparation; for example, the Boston Bowel Preparation Score (BBPS) which is a four-point (0-3) validated scoring system applied to each of three broad regions of the colon (right, transverse, and left colon) after thorough cleansing measures [7]. The BBPS eliminates subjective terms such as "excellent," "fair," and "poor," with objective measures of bowel cleanliness which may be subject to scrutiny during litigation [7].

Patients that have a poor or suboptimal preparation where polyps $>5 \mathrm{~mm}$ in size could be missed should be documented as such and rescheduled to undergo a repeat colonoscopy at a shorter interval (1 year or less) [4]. Adequate bowel preparation carries the implication that the recommended interval before the next colonoscopy will be consistent with published guidelines [5]. Adherence to surveillance recommendations is increasingly being recognized as an indicator of endoscopic procedural quality, as overutilization exposes patients to cost and risk of unnecessary procedures and underutilization could increase the risk of patients developing cancer [8].
High-quality withdrawal technique involves several components: (1) careful examination of the proximal sides of the ileocecal valve, flexures, haustral folds, and rectal valves; (2) adequate distension; (3) removal of fecal material or retained fluid; and (4) adequate viewing time [4]. Furthermore, given the substantial percentage of right-sided colon cancer with microsatellite instability and flat sessile serrated right colon polyps, consider a second look at the right colon or right colon retroflexion during your early years of practice. You should use standard verbiage within the procedure report to reflect quality examination technique. In addition, withdrawal time should be documented and measured in all colonoscopy examinations [5]. The performance target for withdrawal time is $\geq 6 \mathrm{~min}$ for negative screening colonoscopies, which increases the detection of significant neoplastic lesions while decreasing the development of interval cancers when compared to withdrawal times of $<6 \min [5,9]$.

\section{What Important Measures of Quality Should I Be Aware Of?}

One essential quality measure is the adenoma detection rate (ADR), which equates to the percent of patients age 50 and over undergoing a first-time screening colonoscopy who have at least one adenoma removed. This quality indicator, which is easy to calculate, is an important personal quality measure in that it not only documents adequate mucosal examination, but also builds confidence in your recommendations for appropriate surveillance intervals. In fact, ADR is now included in Medicare's mandatory Physician Quality Reporting System (PQRS) as a reportable measure for practitioners to disclose should they wish to qualify for optimal reimbursement. The value of the ADR is well documented in large studies, with ADR correlating inversely with colorectal cancer incidence and mortality [5]. Guidelines have therefore established a minimum target for overall ADR of $\geq 25 \%$ ( $\geq 30 \%$ in men, $\geq 20 \%$ in women $)$ [5]. If your ADR falls below minimal published standards, you should take steps to improve your examinations, such as utilizing a more meticulous mucosal inspection, improving withdrawal time, retroflexing in or examining the right colon twice, using water exchange, or having a nurse observe the procedure [5]. As a new practicing physician, it is important to monitor your quality measures and adjust as necessary to meet minimum standards.

\section{Take Home Message}

Colonoscopy is imperfect, with even the most careful endoscopists being at risk of missing lesions. New graduates who utilize the standard of care quality indicators as 
described above, provide properly explained and executed informed consent (including mention of missed diagnosis), and continually monitor personal ADR should be confident in their ability to provide colonoscopy of sufficient quality to optimally care for their patients while also protecting themselves from litigation.

Authors contribution All authors contributed to the concept, outlining, writing, and editing of the article.

\section{Compliance with ethical standards}

Conflict of interest None.

\section{References}

1. Hernandez LV, Klyve D, Regenbogen SE. Malpractice claims for endoscopy. World J Gastrointest Endosc. 2013;5:169-173.

2. Feld KA, Feld AD. Risk management and legal issues for colonoscopy. Gastrointest Endosc Clin N Am. 2010;20:593-601.
3. van Rijn JC, Reitsma JB, Stoker J, Bossuyt PM, van Deventer SJ, Dekker E. Polyp miss rate determined by tandem colonoscopy: a systematic review. Am J Gastroenterol. 2006;101:343-350.

4. Rex DK, Bond JH, Feld AD. Medical-legal risks of incident cancers after clearing colonoscopy. Am $J$ Gastroenterol. 2001;96:952-957.

5. Rex DK, Schoenfeld PS, Cohen J, Pike IM, et al. Quality indicators for colonoscopy. Gastrointest Endosc. 2015;81:31-53.

6. Harewood GC, Sharma VK, et al. Impact on colonoscopy preparation quality on detection of suspected colonic neoplasia. Gastrointest Endosc. 2003;58:76-79.

7. Lai EJ, Calderwood AH, Doros G, et al. The Boston Bowel Preparation Scale: a valid and reliable instrument for colonoscopyoriented research. Gastrointest Endosc. 2009;69:620-625.

8. Lieberman DA, Rex DK, Winawer SJ, et al. Guidelines for colonoscopy surveillance after screening and polypectomy: a consensus update by the US multi-society task force on colorectal cancer. Gastroenterology. 2012;143:844-857.

9. Shaukat A, Rector TS, Church TR, et al. Longer withdrawal time is associated with a reduced incidence of interval cancer after screening colonoscopy. Gastroenterology. 2015;149:952-957. 